\title{
Study on the Development Path of Smart Community Pension Service in Jiangxi Province
}

\author{
Tanying Li, Sha Wu, Shuangyan Yu* \\ Jiangxi University of Traditional Chinese Medicine \\ Nanchang, Jiangxi 330004, China
}

\begin{abstract}
Home-based pension service of smart community is a new concept proposed under the background of "Internet + " and the concept is in line with Chinese care culture and habits. This paper analyzes and summarizes the current situation and existing problems of community pension service in Jiangxi Province through questionnaire survey and interview. Also, this paper comes up with a development path which is to build a model that combines online and offline activities, establish a diversified capital investment mechanism, strengthen the ranks of elderly service personnel, improve the quality standards of community pension services, strengthen oversight and increase publicity and promotion of home-based pension service of smart community.
\end{abstract}

Keywords-smart community; pension service; development path; Jiangxi

\section{INTRODUCTION}

It is the wish of every old man to depend on and enjoy his old age. With the deepening of the aging of society, it has become an urgent focus to let the elderly age with dignity. According to statistics, by the end of 2017, there were 6.7343 million people aged 60 or above in Jiangxi province, accounting for $14.57 \%$ of the total population. Compared with the whole country, the proportion of the elderly over 60 in Jiangxi province is $2.73 \%$ age points lower than that of the whole country, but the elderly population in Jiangxi province is increasing at the rate of $3 \%$ to $4 \%$ every year, highlighting the grim situation of population aging in Jiangxi province. Through literature collection and field investigation [1-3], this paper, according to the situation of aging in Jiangxi province, in the full respect for the elderly living habits and traditional concept design conforms to the economic and social development of Jiangxi province on the basis of present situation and the development level of intelligence community endowment service development path, in order to make reference to the development of pension services in Jiangxi province.

\section{DATA SOURCES AND METHODS}

According to the geographical location and economic development level of Jiangxi province, this study selected Nanchang city and Ganzhou city as research cities by stratified random sampling method. A total of 200 questionnaires were issued in the two cities, and 196 questionnaires were collected, with a recovery rate of $98 \%$. In addition, interviews were conducted with staff of community endowment service center, and the questionnaire results and interview results were statistically analyzed to analyze the current situation and existing problems of community home-based endowment in Jiangxi province.

\section{RESULTS AND ANALYSIS}

\section{A. Results of questionnaire survey and interview}

The research group conducted a survey of 200 elderly people in the community. Statistics on the main issues are as follows. Thirty-nine $\%$ of the elderly take care of their own families, $33 \%$ live with their children, $9.5 \%$ choose institutions and $18.5 \%$ choose community home-based care. Only $13 \%$ of the elderly and their families knew about smart community care, while $63.5 \%$ needed home-based care from the community [4-6]. The elderly pay attention to community home-based care services: the ratio of catering to housekeeping is $51.5 \%$, the ratio of medical care and rehabilitation is $75 \%$, and the ratio of leisure and entertainment is $57 \%$,spiritual comfort was $53.5 \%$, and legal services $39.5 \%$. $68.5 \%$ of the elderly hope to improve the service for the aged in terms of improving the service facilities for the aged, 52\% hope to improve the service for the aged in terms of improving the quality of staff, and $71 \%$ hope to improve the service for the aged in terms of improving the service projects for the aged.

In the field research, we conducted interviews with the staff of the community home care service center from three aspects. The first is basic information. Including what homebased care services the smart community provides; The hardware facilities of the center and the construction of the intelligent endowment platform; Intelligent community pension service professionals, etc. Second, the operation of smart community service centers for the aged. It includes the mode of smart community pension service, the system of the center, the cost of community pension service, the use of the fund source of the center, and the evaluation and supervision of the center [7]. The third is the existing problems and improvement Suggestions. Including staffing issues and recommendations; Problems and Suggestions in service use; Difficulties and Suggestions of fund input and use; Suggestions on the management and operation of the center. 


\section{B. Result analysis}

At present, the basic pension service system in Jiangxi province has been preliminarily established, and the community home-based pension service has achieved certain results. However, from literature collection and field research, there are also some problems and difficulties, which are mainly reflected in the following aspects: First, The pension service center is short of fund investment, insufficient fund support and single financing channel. Second, there is a shortage of senior care personnel, most of whom are of low quality. Third, the infrastructure of community home-based care centers is weak, and urban and rural development is unbalanced. Fourth, community home-based care service standards are not uniform, lack of industry supervision and evaluation mechanism; Fifth, community home care social awareness is not high, publicity is not strong; Sixth, the level of informatization is low, and the integration of medical care and nursing is not strong enough and so on.

\section{DISCUSSION AND SUGGESTIONS}

Population aging is a major social problem that Jiangxi province and even the whole country must face and solve for a long time. Based on the current situation of community homebased elderly care services in Jiangxi province, the development path of intelligent community elderly care services in Jiangxi province is proposed based on the existing problems and the successful practical experience in Wuzhen.

\section{A. Build a combined mode of "online + offline"}

From the field survey, the elderly service information platform in some pilot areas in Jiangxi province has a low participation rate and serious waste of resources due to imperfect platform construction, insufficient information resources, weak publicity and other factors. At the same time, the survey also found that many community home care service centers (stations) service content is not rich, nursing rehabilitation, legal rights and spiritual comfort and other professional services are relatively lack; Moreover, the homebased elderly care service mode is relatively single, which mainly focuses on designated service, and fails to combine the designated service with door-to-door service.

Smart community home-based care for the aged is a new model that combines the Internet, cloud computing, Internet of things, big data and other services for the aged to innovate community home-based care services, namely "online + offline" mode. The "online" platform includes the intelligent pension comprehensive service management platform and medicine platform, among which the intelligent pension comprehensive service management platform includes the basic data of service objects and pension service information database, social pension service resource database, call center system and comprehensive information management system. "Offline" is community home endowment service centers and community health service station, which is based on community home endowment service center, to carry out the community centered care and home care, occupy the provide life care, health care and rehabilitation, professional care, leisure and entertainment, emergency rescue and spiritual solace, pension services such as diversifying community home endowment service content, the greatest degree meet the demand of old man multilevel and diversified services.

\section{B. Establish diversified capital investment mechanism}

Jiangxi is a traditional agricultural province in China, and the level of social and economic development is still relatively lagging behind. In addition to the community home care service just pilot started, the investment in community home care service across the province is generally seriously insufficient. For example, Nanchang, the provincial capital, provides subsidies of 80,000-100,000 yuan for the construction of new home-based old-age care service centers and 10,000-30,000 yuan for the operation, which are seriously lower than the normal construction and operation standards. At present, the funding sources of community home-based care services in Jiangxi province are mainly government grants, financial subsidies, charitable donations, etc., and lack of diversified and sustainable sources of funds such as social financing and individual donations.

Community home-based care for the aged is a basic project for people's livelihood. First, governments at all levels should increase financial input, gradually establish special funds for community home-based care, and strengthen supervision over the use of funds to ensure that the funds are used exclusively. At the same time, we will further improve subsidies for the construction and operation of community home-based elderly care service sites, and expand the coverage of community home-based elderly care services purchased by the government. Second, perfect the preferential policy support, such as shall be exempted from business tax, value-added tax, business tax and value-added tax or given preferential income tax or exemption of the relevant administrative undertaking charges, etc., to encourage and mobilize social capital investment community home endowment service enterprise, establish the government, enterprises, non-profit organizations and individual citizens and other diversified funding mechanism. Third, the role of welfare lottery welfare fund and sports lottery welfare fund should be further played, and a certain proportion of funds should be allocated for undertakings for the aged in accordance with regulations.

\section{Strengthen the construction of talent team for elderly service}

According to the survey, most practitioners of community home-based care services are "4050"(born in the 1960s and 1970s) staff with low education level, lack of professional skills, and lack of professional nursing qualifications. In addition, the social status and welfare of home-based elderly care service personnel are relatively low, which leads to a lack of human resources and serious brain drain of rehabilitation and nursing professionals. At the same time, most of the management staff of the community home care service center are part-time members of the community neighborhood committee, and the service is not timely and the operation is not professional.

It is one of the primary tasks to strengthen the construction of the professional talent team and ensure the supply of talent resources for the elderly care at home. First of all, we should increase the training of pension service professionals. On the one hand, we will continue to offer programs related to 
rehabilitation of traditional Chinese medicine, health maintenance of traditional Chinese medicine, geriatrics, health service and management in more general undergraduate colleges, and encourage various vocational colleges to set up programs or courses related to elderly care services. Governments everywhere, on the other hand, increasing financial support, family endowment service personnel training, vigorously implement system of card mount guard, a practicing certificate "endowment nurse" as a community home endowment service agencies to hire employees, and one of the important index for evaluation agency service quality, in order to improve the whole quality of community home endowment service team. Secondly, an effective talent incentive mechanism should be established to improve the salary and welfare of the elderly service industry and enhance the attractiveness of the elderly service industry. For example, Nanchang city, through carrying out "the most beautiful nursing staff" commendation, strengthen positive publicity, and constantly improve the social status of nursing staff. Third, promote the development of elderly service volunteer team. The community should actively publicize policies and regulations on old-age service, and extensively mobilize people from all walks of life to carry out voluntary activities for the elderly in their spare time through public opinion publicity. At the same time, the management method of elderly service volunteers is formulated, and the specific standards and operating rules of volunteer recruitment, registration, training, induction and incentive are clarified. The "time bank" has been introduced to provide mutual care for the elderly. The time spent volunteering for the elderly can be deposited into the "time bank", which can be used for their own or their family members' pension services in the future.

\section{Improve the quality standard of community pension service and strengthen supervision}

Industry standards and market norms are the basis for promoting community home-based care services. In order to better guarantee the scientific and standardized development of smart community home-based care services, it is suggested to establish and improve the quality evaluation standard system of community home-based care services. The standard system includes hardware system and software system. The hardware system specifically includes infrastructure and intelligent service platform standards, among which infrastructure refers to office facilities, living facilities, medical and health care facilities, cultural and sports facilities and security preparedness facilities; Intelligent service platform is evaluated from the aspects of ease of use, economic application level, sensitivity and false alarm rate. The software system is mainly about the service function, service personnel and service effect of community pension service center. At the same time, it should also establish a supporting mechanism for the quality evaluation and supervision of elderly care services. Evaluation subjects should include self-evaluation, evaluation of service objects, evaluation of street offices and evaluation of third-party social institutions, especially the evaluation of third-party social institutions.
In addition, we should increase the publicity and promotion of smart community home-based care services. On the one hand, policies and regulations on old-age care services can be widely publicized through $\mathrm{TV}$, radio, newspapers, Internet and other media. On the other hand, information related to home-based care services can be actively publicized through community publicity boards, community WeChat official accounts and other channels, so as to make the whole society more aware of home-based care services in smart communities. Elderly people and their families are willing to accept home-based care services in smart communities.

\section{CONCLUSION}

In recent years, Jiangxi province has issued relevant policies and regulations, and put forward to accelerate the construction of a multi-level old-age service system based on home, supported by community and supplemented by institutions. According to statistics, there were 6,430 homebased care centers in Jiangxi province by January 2016. According to the provincial plan, by 2020 , the province will build 13,000 community home-based care centers, and at least one home-based care information center will be established in each district-based city. There should be no less than 3,000 urban home and community service facilities for the aged, covering $100 \%$ of the population. There are no less than 10,000 rural home and community service facilities for the aged, covering more than $60 \%$ of the population.

Smart community pension service is a new concept put forward under the background of "Internet +", which is in line with Chinese pension culture and habits. It is an important exploration of community service and the development direction of future pension model. Smart community homebased care combines the advantages of family care and institutional care, makes up for the weakness of family care function and the immature development of institutional care, complies with the traditional concept of the elderly, and realizes the aspiration of the elderly not to leave home. Through the development of the intelligence community endowment service, establish an "Internet + elderly care" service network with complete functions and four-level linkage, namely, "Internet + elderly care" service network of home-based elderly care service centers of cities, counties (districts), towns and (streets)community, promoting community home endowment service resources and community medical resources integration, promote the medical combination, meet the needs of the elderly all aspects and improve the comfort and happiness, the old man's life truly achieve the elderly are provided for treated, taught, learned, engaged and happy. 


\section{ACKNOWLEDGMENT}

First author: Li Tanying (1972 - ), female, Ganzhou, Jiangxi province, lecturer, mainly engaged in the teaching of pharmaceutical enterprise management courses.

Corresponding author: Yu Shuangyan (1963 - ), female, from yiwu, Zhejiang, professor, master's tutor, mainly engaged in the teaching of pharmacy administration, pharmacy law and other courses. Email: 444639882@qq.com.

Fund project: Jiangxi province (2017) social science planning project--Study on the development path of smart community pension service of Jiangxi. (Project Serial number:17SH08)

\section{REFERENCES}

[1] Nanchang with home and community endowment service reform pilot study. (In Chinese). http://www.jxmzw.gov.cn/system/2019/08/06/018543179.shtml,2019-82

[2] Current situation analysis and countermeasures for home-based elderly care service in ganzhou city (In Chinese). http://www.docin.com/p1496653967.html,2016-4-25.

[3] Shujuan Yang, Jianxing Zhang, Yachun Ding et al. Research on factors influencing the demand for community pension services in Changchun [J]. Chinese Health Service Management,2019 (7) :485-488. (In Chinese)

[4] Tanying Li, Kai Huang, Shuangyan Yu. Research on the construction of intelligent community pension service system under the background of combining medical care and nursing [J]. ZHONGGUO NONGCUN WEISHENG SHIYE GUANLI 2018 (9) : 1140-1143. (In Chinese)

[5] Li Chen, Qin Lu, Jingjing Qiao. Research on the construction of smart community pension service system [J]. POPULATION JOURNAL, 2016, 38(3):67-73. (In Chinese)

[6] Li Hao, Weijian Zhang . Construction of an integrated smart community pension model based on big data: medical care-pension-insurance[J], Chinese Journal of Gerontology, 2017 (1):226-228. (In Chinese)

[7] Hailong Zhu. Intelligent elderly care: innovation and reflection of Chinese elderly care model [J], HUNAN SHIFAN DAXUE SHEHUI KEXUE XUEBAO, 2016 (3):68-73. (In Chinese) 